\title{
InTEgrating Human FaCtor Considerations into CAPSTONE Design Projects
}

\author{
Holly R. Algra \& Clifton R. Johnston \\ Dalhousie University, Mechanical Engineering Department \\ Holly.Algra@dal.ca, Clifton.Johnston@dal.ca
}

\begin{abstract}
Engineers are, in general, poor at considering human factors in our designs. Human factors are an important aspect of engineering design that must be introduced and nurtured in all engineers, but is a challenging problem. We have undertaken a case study of a past capstone design project to evaluate how human factors were considered. This paper will present a case study of this project's application of human factors.

Our work hopes to identify what influenced an increased consideration of human factors, which led to the success of this project. A combination of diversified backgrounds may have played a significant factor in the design process, but there were, however, likely other factors that impacted the team's performance. Our ultimate goal is to use the information gained from this case study to develop training and design tools to increase usability of other projects.
\end{abstract}

Keywords: Human Factors, Design Methodology, Capstone Design Project, Design for Usability

\section{INTRODUCTION}

Design, and the process of designing, has said to be above all else, the difference between an engineering education and a science education [6], which is only emphasized by the fact that both the Canadian and American Engineering Accreditation Boards hold standards for design within accredited undergraduate programs [2] [1]. The task of how to incorporate design, how best to teach it, continues to be a challenge, as shown by the large scope of literature describing the best pedagogical method [5] [7] [8] [11]. One thing that seems to be agreed upon is the idea that design is not a linear activity [8], which has resulted in a shift to increased industry participation, increased time devoted to openended, 'messy' problems. With the inclusion of real life problems comes the inclusion of real users and clients. Human factors are not typically addressed in engineering education, and as a result, students also often overlook them in their design processes. The reasons for this are often attributed to their increased focus on technology, specifications, and engineering science over the more subjective field of usability. This becomes especially apparent in capstone design projects, when engineering students are given and asked to work on year-long projects often with industry clients and real life problems that demand a working solution. Human factors are an important aspect of engineering design that must be introduced and nurtured in all designers, including engineers. How to best approach developing human factor skills in engineering students is a particularly challenging problem.

The focus of this case study is a capstone design project from the Department of Mechanical Engineering at Dalhousie University. The project was sponsored by a company which asked the students to create a system that would mimic the inside of a seaplane for crash simulation purposes. The company currently offers training of helicopter evacuation techniques, modeling and simulating aircraft being submerged in water for more thorough and realistic safety training, and wished to expand into seaplanes.

\section{CASE STUDY}

The group writes in their final report that the project was considered a huge success and that they have achieved and surpassed the design criteria; that overall, the project was a success and client was satisfied with the results [9]. Others also agreed on the success, as their project was ranked the top among their class by both professors and fellow students. At their final presentation, they mentioned repeatedly the many human factors present in their design- the desire for limited required tools, the fact that two people had to be seated in it, the assembly time, the consideration of a gloved hand in the handle, the default locked pin position. Due to the inclusion of these rarely considered aspects in the design, we felt it would be an interesting project to evaluate and hopefully identify the methods used to address the human factors in the project as a way to replicate or inspire the same in future projects.

This work hopes to identify what factors influenced an increased consideration of human factors, 
of use environment, of installation procedures - factors that are often overlooked by engineering designers, and which led to the success of this project. This project began at the final design presentation, and continued by reading through the team's final report. Other submitted work, such as the testing summary, the project inspection report, and the fall term reports were also examined, which is presented in this paper. In the future, we plan on examining their logbooks, interviewing the team, as well as interviewing their project supervisor and the client are also planned for future steps.

Our initial research identified that this team was formed from diverse students including mature students with previous degrees, and varying personal interests, such as performing arts, theatre construction, construction, the outdoors, and previous work experience in the field of Maritime risk. This combination of diversified backgrounds may have played a factor in the design process- an idea that would explain the presence and encouragement of diversified teams within design firms. There were, however, other factors that likely impacted the team's performance. An examination of their final report indicated that many of the human factor requirements and suggestions originated from the client, who insisted on many of the considerations based on the existing platforms that exist for helicopter training.

The company provided a clear description of what they required, which the team disseminated into a list of quantifiable requirements [9], which are as follows:

1. Must integrate into the existing Modular Egress Training Simulator (METS). Specifically, it can be contained within the $1.65 \mathrm{~m}$ wide $\mathrm{x} 1.78$ $\mathrm{m}$ high $\times 4.26 \mathrm{~m}$ long frame and it will work with the existing metal grating.

2. Must accommodate at least two people at a time for training.

3. The seat orientation must be adjustable to three different positions: $0^{\circ}, 45^{\circ}$, and $90^{\circ}$.

4. Must meet or exceed the anti-corrosion characteristics of the current METS module.

5. Must meet or exceed the loading characteristics of the current METS module.

6. Must facilitate flexibility for simulation parameters (eg. door or window release)

7. Must be able to be installed into a METS from storage by a two-person crew in two hours or less.

8. The seating must be able to re-orient in 30 minutes or less during a training session.

In addition, some desirable qualities were indicated, including matching the egress path to an existing METS egress path, using either a single or no tool for installation, and minimal part failure risks while in operation [9]. As we can see, at least three of the requirements $(2,7$, and 8$)$ as well as the desire for limited tooling are directly related to usability. Reference to other human factors, such as the environmental consideration that a user would be wearing gloves, was stated in the final presentation, but there was no mention of it in any of the reports. Because of the lack of documentation, it is unsure whether this was designed for or an afterthought. One additional consideration that was noted throughout the report was the safety feature of a passively locked pin, which required insight into typical use scenarios. Considerations made by the team also seemed to be very indicative of the fact that they considered themselves to be typical users. The team, who knew the design and setup quite intimately, performed all assembly tests and Requirement 2 was considered complete because two of the team members were able to fit in the completed design. Whether the team considered anthropometrics to determine that they were representative of typical users is unclear. The documentation showed no consideration of anthropometrics or biomechanics in any of the sizing or the physical installation requirements.

This study has only looked thus far into the official documentation and final presentation given by the team. Further investigation into their individual logbooks and personal communication with the client, the team members and the supervisor is expected to provide some insight into more detailed thought processes of the team members.

\section{DISCUSSION}

The project was a success, and the team members did a commendable job of incorporating human factors into the final design. It is believed that many of the considerations originated from a client who was descriptive and insistent on the inclusion of the human factors in the design. The work of translating and meeting those requirements into a workable, accomplishable design is in itself a comment on the creativity and engineering skills of this team. The team had a difficult task in front of them, but they had the advantage that a major hurdle had already been overcome. By providing a project definition riddled with human factors requirements, the team could focus on the implementation of those ideas, but the execution of solutions is typically where engineers succeed. The inclusion of usability and human factors from the beginning, the empathy required in the beginning problem definition is usually where the most ignored obstacle lies, for "the first design process step of determining the problem is known by every designer to be the most difficult part of design [3]".

Caswell [3] cautions that the retrospective view of a successful design breaks down when a novice attempts to apply the process to a real design project, as suggestion and portrayal of other design processes does not necessarily translate well to application. Perhaps the tool we need, then, is not to encourage students to simply 
think about human factors while doing their project, but to incorporate them so fully into the design requirements that a successful design cannot exist until the human factors are not only considered, but designed for and around. Cohen recently commented in an article about design thinking that a big part of this concept involves empathy for those you are designing for, suggesting that empathize comes earlier in the design process than defining or ideation [4].

The tool that results from this work, then, is the realization that only making students aware of the necessary presence of human factors is not enough, "the realities of innovation and creativity are much more complicated than simply a willingness to be more creative [4]." Helping them to recognize that the need for usability is present from the start of projects and to integrate it into the project definition and requirements will increase the empathy and user-focused designs. Through a deeper look at the problem definition this team utilized, we hope to be able to implement that technique in other projects.

\section{CONCLUSIONS}

This case study investigated the execution of a capstone design project. There were several factors attributing to the success of the project, including a hardworking, motivated team of intelligent, diverse students. Additionally, the clear vision and the specific problem definition from the client created an environment in which the team's efforts could be directed to a well-executed solution. The company, whose president has an M.Ed, has a rigorous devotion to usability, with the reputation of the company built on safety training through experiential learning. As we look at the logbooks and perform interviews with the team, the client and supervisor, we hope to better educate engineering students how to incorporate human factors not only in the execution and implementation phases, but also in the problem and requirement definition.

Design is becoming increasingly human-focused as clients and customers demand intuitive and creative projects. Designers who become aware of this, basing their focus and requirements not only on technical specifications, but who also move deeper into the problem definition to include those using, manufacturing, and repairing their products, will be more successful. This does not mean that process, rationality, and analysis are discarded [3], but that tools are added to them to move design projects further into a realm where messy problems can be approached with innovative, humanfocused, and creative solutions. There is no checklist to rigidly follow to attain a well-designed product. As Kathleen McLean, exhibit designer, states that "no one key will do the trick- we need the whole key ring at our disposal so we can decide which keys to use for specific purposes" [10]. Human factor considerations may not be the sole key on our key ring, but it is a key that opens doors to increase empathy and, therefore, the likelihood of a creative, innovative, and successful design.

\section{References}

[1] ABET Engineering Accreditation Commission, 2012-2013 Criteria for Accrediting Engineering Program. Baltimore, MD: ABET, 2011, Available as of April 10, 2014 from http://www.abet.org/uploadedFiles/Accreditation/Accreditati Ac Process/Accreditation_Documents/Current/eac-criteria2012-2013.pdf

[2] Canadian Engineering Accreditation Board, 2013 Accreditation Criteria and Procedures. Engineers Canada, 2013

Available as of April 10, 2014 from

http://www.engineerscanada.ca/sites/default/files/sites/defau 1t/files/accreditation_criteria_procedures_2013.pdf

[3] D.J. Caswell, C.R. Johnston, O.R. Fauvel, D. Douglas, and M. Eggermont, "Fundamentals of a First-Year Engineering Design and Commnication Course: Familiarization, Functionality and Testing," in Proc. American Society for Engineering Education Annual Conference and Exposition, ASEE2004, Session 1793

[4] Reuven Cohen, Design Thinking: A Unified Framework For Innovation. Forbes, 2014,

Available as of April 10, 2014

fromhttp://www.forbes.com/sites/reuvencohen/2014/03/31/d esign-thinking-a-unified-framework-for-innovation/

[5] Kaija Collin, "Connecting work and learning: design engineers learning at work," Journal of Workplace Learning, vol. 18, no. 7/8 pp. 403-413, 2006.

[6] B.K Hodge, and W. G. Steele, "Experiences with a Curriculum with Balanced Design Content in All Stems," in ASEE Annual Conference Proceedings, vol 1, 1995, pp. 1981-1986

[7] Sanjeev Kumar and J. Kent Hsiao, "Engineers Learn 'Soft Skills the Hard Way': Planting a Seed of Leadership in Engineering Classes," Leadership and Management in Engineering, vol. 7, pp. 18-23, 2007.

[8] Gay Lemons, Adam Carberry, Chis Swan, and Chris Rogers, "The benefits of model building in teaching engineering design,” Design Studies, vol. 31, pp. 288-309, 2010 .

[9] Aeneas Maddalena, Andrea Felling, Anthony Lord, and Gina Marin, Seaplane Crash Simulator MECH 4010- Term Report Halifax, NS: Dalhousie University, 2013 Available as of April 10, 2014 from http://poisson.me.dal.ca/ dp 12 10/deliverables.html

[10] Kathleen McLean, "Introduction: Best Practices Should be a Tool, Not a Rule," in Are We There Yet, Kathleen McLean and Catherine McEver (ed.), 2004. 
Proc. 2014 Canadian Engineering Education Association (CEEA14) Conf.

[11] Kristin L. Wood, Daniel Jensen, Joseph Bezdek, and Kevin N. Otto, "Reverse Engineering and Redesign: Courses to Incrementally and Systematically Teach Design," Journal of Engineering Education, vol. 90, no. 3, pp. 363-374, 2001.

CEEA14; Paper 131 